\title{
ALOCOM: a generic content model for learning objects
}

\author{
Katrien Verbert • Erik Duval
}

Published online: 11 June 2008

(C) Springer-Verlag 2008

\begin{abstract}
Learning organizations are focusing heavily on learning content reusability. The ultimate objective is a learning object economy characterized by searchable digital libraries of reusable learning objects that can be exchanged and reused across various learning systems. To enable such approach, basic questions of learning content interoperability need to be addressed. This paper investigates the interoperation of learning content defined according to different specifications. A number of content models are reviewed that define learning objects and their components. On the basis of a comparative analysis, the content models are mapped to a generic model for learning objects to address interoperability questions and to enable share and reuse on a global scale.
\end{abstract}

Keywords Content models - Ontologies · Reusability · Interoperability

\section{Introduction}

Barriers and enablers for the reusability of learning objects are important research topics in the learning technology community. In various publications, it is argued that reuse not only saves time and money [11,34], but also enhances the quality of digital learning experiences, resulting in efficient, economic and effective learning [13].

There is an inverse relationship between the size of a learning object and its reusability [45]. As the size of the

K. Verbert $(\varangle) \cdot$ E. Duval

Department of Computer Science, K.U. Leuven,

Celestijnenlaan 200A, 3001 Leuven, Belgium

e-mail: katrien.verbert@cs.kuleuven.be

E. Duval

e-mail: erik.duval@cs.kuleuven.be learning object decreases (lower granularity), its potential for reuse increases. Size is thus an important factor for enabling successful learning object reuse. However, this size is only vaguely defined by learning object definitions [35].

According to the learning object metadata (LOM) standard, a learning object is "any entity, digital or non-digital that may be used for learning, education or training" [12]. This definition allows for an extremely wide variety of granularities [35]. In one sense, this is appropriate, as there are a number of common themes to content components of all sizes. In another sense although this vagueness is problematic, as it is clear that authoring, deployment and repurposing are affected by the granularity of the learning object [13].

Learning object content models address this problem. The models define different kinds of learning objects at different levels of granularity and are based on the belief that we can create independent and self-contained learning content, which may be used alone or dynamically assembled, to provide "just enough" or "just-in-time" learning. On top of that, these learning components can be combined to form longer educational interactions or reused in different learning contexts [40].

However, there are many different content models and learning object definitions across these models vary considerably. Some models define learning objects as lessons, while others relate learning objects to concepts, principles, facts, procedures or processes. The heterogeneity of definitions is a barrier for learning content reuse on a global scale, as it is unclear whether content can be reused or repurposed in a different context.

In an earlier work, we developed an abstract learning object content model (ALOCOM) for content model interoperability [42]. On the basis of the definition of the NETg [22], SCORM [37], Cisco [3] and Learnativity [44] content models, we specified a model that defines three general 
aggregation levels. The models were mapped to our model to address interoperability questions.

In this paper, we present an extended version of this work. Nine content models have been analyzed in detail. To enable their interoperability, an ontology has been developed that builds upon our earlier work. The abstract learning object content model has been detailed, specifying content classifications and relationships between content components and mappings have been implemented between content models according to the method introduced in [6]. The method has three main stages:

- building a global ontology that covers existing content models

- building local ontologies for each content model, and

- defining mappings between the ontologies.

Mappings can enable share and reuse of learning objects across digital libraries. Learning object components stored in an SCORM digital library can, for instance, be identified and potentially repurposed in the context of a Cisco or NETg learning system.

To facilitate the description and comparison of learning object content models, we first briefly introduce content classification schemes that are used by the investigated content models for defining granularity levels. In Sect. 3 , the content models that were included in the investigation are presented and Sect. 4 presents a comparative analysis. The method used for implementing mappings is described in Sect. 5. The global ALOCOM content model is presented in Sect. 6, local content model ontologies in Sect. 7 and mappings in Sect. 8. How this work connects to RAMLET [31], an IEEE standard under development, is discussed in Sect. 9. Use cases are described in Sect. 10 and related work is discussed in Sect. 11. Finally, conclusions and remarks on future work conclude this paper.

\section{Background}

Learning object content models define different levels of content components, the properties of these components, such as granularity, and how these components can be aggregated [35]. To define granularity levels, different classification schemes are used by current content models, such as the structured writing methodology developed by Horn [18] or the classification of Ballstaedt [2]. To facilitate the description and comparison of content models, we briefly introduce the classifications in this section.

\subsection{Structured writing}

The structured writing method of Horn [18] was developed for instructional developers and business writers to prepare clear and concise training manuals, proposals, reports and memos. The methodology should enable managers, sales people, office personnel, and technicians to learn new products, services, and operating procedures rapidly and precisely.

In the methodology, a paragraph is replaced by an information block, a chunk of information that is organized around a single subject, containing one clear purpose. Horn defined 200 types of information blocks, including analogy, block diagram, checklist, classification list, classification table, classification tree, comment, cycle chart, decision table, definition, notation, objectives, outlines, parts-function table, parts table, prerequisites to course, procedure table, purpose, rule, synonym, and theorem.

In addition, a set of content analysis categories and question types were defined based on seven information types [17]:

1. Concept: A "concept" describes an abstract or generic idea generalized from particular instances. A concept is used for teaching a group of objects, symbols, ideas, or events which are designated by a single word or term, share a common feature and vary on irrelevant features [3].

2. Fact: A "fact" provides information based on real occurrences; it describes an event or something that holds without being a general rule [41].

3. Classification: A "classification" is a sorting of items into categories. A typical example is "overview of technologies within medical imaging" [8].

4. Structure: A "structure" is a physical object or something that can be divided into parts and has boundaries. A typical example is "the anatomy of the human brain" [8].

5. Principle: A "principle" is a basic generalization that is accepted as true and that can be used as a basis for reasoning or conduct [41].

6. Procedure: A "procedure" consists of a specified sequence of steps or formal instructions to achieve an end. Typical examples are "Euclid's algorithm" or "instructions to operate a machine" [3,41].

7. Process: A "process" describes a sequence of events. A process provides information on a flow of events that describes how something works and can involve several actors. Typical examples are "the process of digestion", and "how a computer system responds to commands" $[3,41]$.

Guidelines were developed that identify which key information blocks are necessary to fully understand a topic. The underlying research focused on a deep understanding of the basic units of a subject matter and provides an easy to understand taxonomy. Developed in 1967, structured writing can 
claim to be the first to define and develop precise modular information blocks that are firmly grounded in a taxonomy of information types [17].

\subsection{IEEE LOM}

The IEEE Learning Object Metadata Standard [12] is a widely adopted standard that specifies the syntax and semantics of learning object metadata [7]. The standard contains two elements that are relevant for describing learning object granularity [35]: Aggregation levels and learning resource types.

Aggregation levels are defined as an enumeration of four types, identified by a number:

1. The smallest level of aggregation, e.g. raw media data or fragments.

2. A collection of level 1 learning objects, e.g. a lesson.

3. A collection of level 2 learning objects, e.g. a course.

4. The largest level of granularity, e.g. a set of courses that lead to a certificate.

Learning resource types describe specific kinds of learning objects by a predefined vocabulary. The following items are included: exercise, simulation, questionnaire, diagram, figure, graph, index, slide, table, narrative text, exam, experiment, problem statement, self-assessment, and lecture. Given its status as an internationally recognized, accredited technical standard, the IEEE Learning Object Metadata Standard is emerging as the primary metadata standard for learning objects [46]. Many learning object content models use LOM metadata for the description of content components.

\subsection{Ballstaedt}

Ballstaedt [2] provides a classification of knowledge representations for paper-based educational books. The distinction is made between textual and non-textual representations. Textual representations are categorized into oral and written texts.

Written texts are further divided into the following categories:

1. Expository texts: these texts contain factual representations of the subject matter to be taught. Such texts may contain definitions and explanations.

2. Narrative texts: narrative texts are subjective descriptions of personal experiences related to some subject matter.

3. Instructions: instructions provide a detailed description of how to perform a procedure step-by-step.

4. Supplementary didactic texts: these texts are didactically motivated elements that support the learning process, classified as learning objectives, advanced organizers, summaries, examples, excursions, glossaries and selfassessments.

Non-textual representations of learning content include charts, tables, diagrams, figures, icons and maps.

In contrast to structured writing and IEEE LOM, the research is not widely disseminated: only the dLCMS content model [35] refers to the classification. The classification might be useful in defining a global content model for learning objects, although, as it is specifically targeted at classifying learning content.

\subsection{The component display theory}

The component display theory of Merrill [26] classifies learning along two dimensions: content and performance. Four types of content (concept, fact, principle and procedure) are crossed with four types of learning performance (remember generality, remember instance, use and find). The content types are contained in the structured writing classification.

In addition, the theory specifies four primary presentation forms: rules (expository presentation of a generality), examples (expository presentation of instances), recall (inquisitory generality) and practice (inquisitory instance). Secondary presentation forms include prerequisites, objectives, helps, mnemonics and feedback.

The theory specifies that instruction is more effective to the extent that it contains all necessary primary and secondary forms. Thus, a complete lesson would consist of an objective, followed by a combination of rules, examples, recall, practice, feedback, helps and mnemonics appropriate to the subject matter and learning task. The theory suggests that for a given objective and learner, there is a unique combination of presentation forms that results in the most effective learning experience [26].

The component display theory provides the foundation for Clark's performance matrix [9]. Clark's performance matrix, along with Merrill's component display theory, can help designers classify instructional outcomes and are developed in some content models, such as the Cisco [3] and Learnativity [44] models.

\section{Overview of learning object content models}

In this section, nine content models are presented that were included in the investigation. Models defined by some of the major players in the e-Learning field are presented first, followed by models that were developed for academic purposes.

\subsection{NETg learning object model}

NETg [22], the National Education Training Group, is a Thomson Learning Company and worldwide leader in 


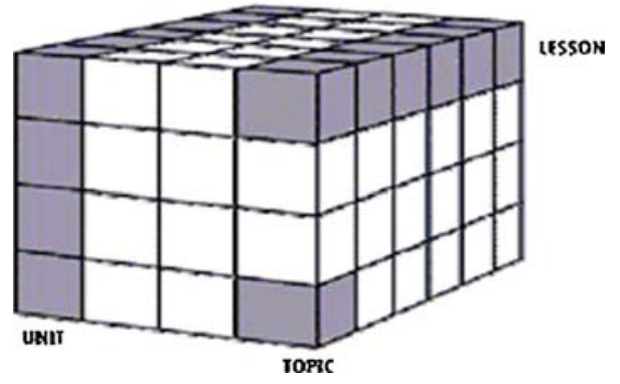

Fig. 1 An NETg course structure [40]

blended learning solutions. In NETg, a course is structured as a matrix (Fig. 1) divided into three major components: units (the vertical), lessons (the horizontal) and topics (the cells) [40].

Each unit, lesson and topic in this structure is defined, in part, by its relationship to the other components.

1. Course: Made up of units

2. Unit: Made up of lessons

3. Lesson: Made up of topics

4. Topic: Contains a single objective, a learning activity and an assessment (see Fig. 2).

A topic is known as an NLO (NETg learning object), which is defined as the smallest independent instructional experience that contains an objective, a learning activity and an assessment that measures the learning objective.

The term learning objective is an instructional design concept that derives from the work of Mager [25], Gagne [16], Dick and Carey [10], and others [32]. A learning objective is a single measurable or verifiable step on the way to a learning objective. Learning objectives say what a learner is expected to do or learn and how an acceptable level of achievement will be verified.

NETg is a member of the IMS Global Learning Consortium and has assembled its own group of learning management system (LMS) developers whose systems are being designed to work with the NLO architecture. Using a tool like NLO+, NETg content can be mixed and matched from various courses to create a new course, tailored to the needs of the learner. When the learner needs a piece of information, she can navigate to the digital library, type in a request, and get relevant NLOs. If the learner needs a full course on a subject, the system will build a course based on the NLOs needed [40].

Approximately 3,000 courses are currently available that are NETg conformant. Course topics include Microsoft, Cisco and Novell Certification training; networking; $\mathrm{COBOL}$ and Java programming; databases; Web development; and ecommerce implementation. These courses contain approximately 75,000 learning objects. Examples of learning objects,

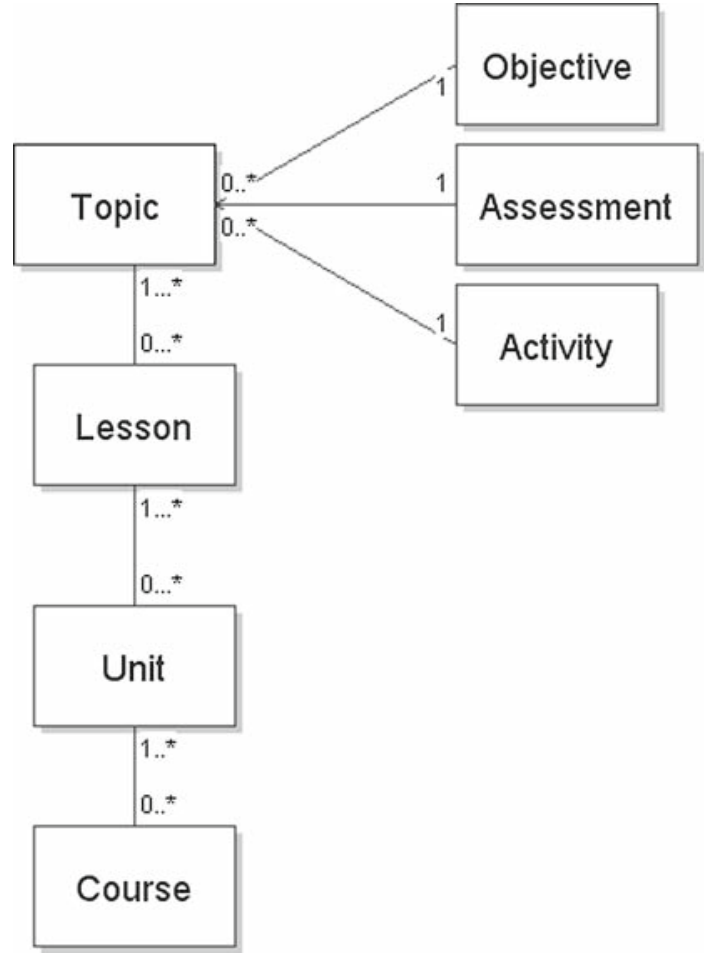

Fig. 2 UML representation of the NETg learning object model

contained in an NETg course on Microsoft Windows 2003, include "Exploring the Word window" and "Creating and saving documents". Such learning objects are designed to take learners 5-7 min to complete and are available in an NETg specific format.

\subsection{Learnativity content model}

The Learnativity foundation has developed a content model that provides a comprehensive description of granularity [44].

The model defines a five level content hierarchy, as illustrated in Fig. 3:

1. "Raw" data and media elements are the smallest level and relate to content elements that reside at a pure data level. Examples include a single sentence or paragraph, images, and animations.

2. An information object combines raw data and media elements and focuses on a single piece of information. Such content might explain a concept, illustrate a principle, or describe a process. Exercises are often considered to be information objects.

3. Based on a single objective, information objects are assembled into the third level of application objects. At this level, reside learning objects in a more restricted sense than the aforementioned definition of the LOM standard suggests [13]. Learning objects are a collection 
Fig. 3 UML representation of the Learnativity content model

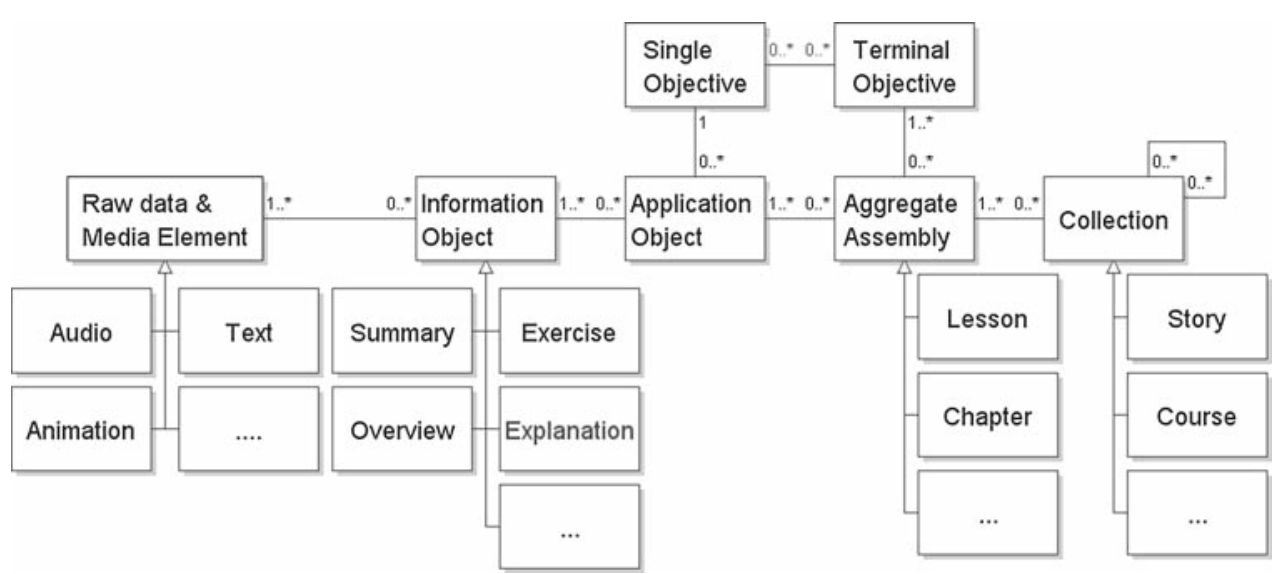

of information objects and relate to a single learning objective.

4. The fourth level refers to aggregate assemblies that deal with larger (terminal) objectives. This level corresponds with lessons or chapters.

5. Lessons or chapters can be assembled into larger collections, such as courses and curricula. The fifth level refers to these collections.

The Learnativity model incorporates concepts found in structured writing [18] and the vocabulary of the LOM learning resource type [12]. Themes found in Clark's writings [9] and in a corporate training white paper published by Cisco Systems [3] are developed in the Learnativity model [32].

The model has gained considerable acceptance in both training and education communities. The model is used as a basis for a model defined in the Reusable Learning Project [32] and has been adopted by the NLII Learning Object Virtual Community of Practice, which is now known as the Educause learning initiative (ELI) [14].

\subsection{SCORM content model}

The most widely implemented set of specifications, intended to allow learning content to be developed independently of a particular delivery platform, is the sharable content object reference model (SCORM) [37], a collection of specifications and standards that is documented and maintained by the advanced distributed learning initiative [1]. SCORM includes a content aggregation model that features:

- Assets

- Sharable content objects (SCOs)

- Activities

- Content aggregations.

A UML representation of the SCORM content model is shown in Fig. 4.

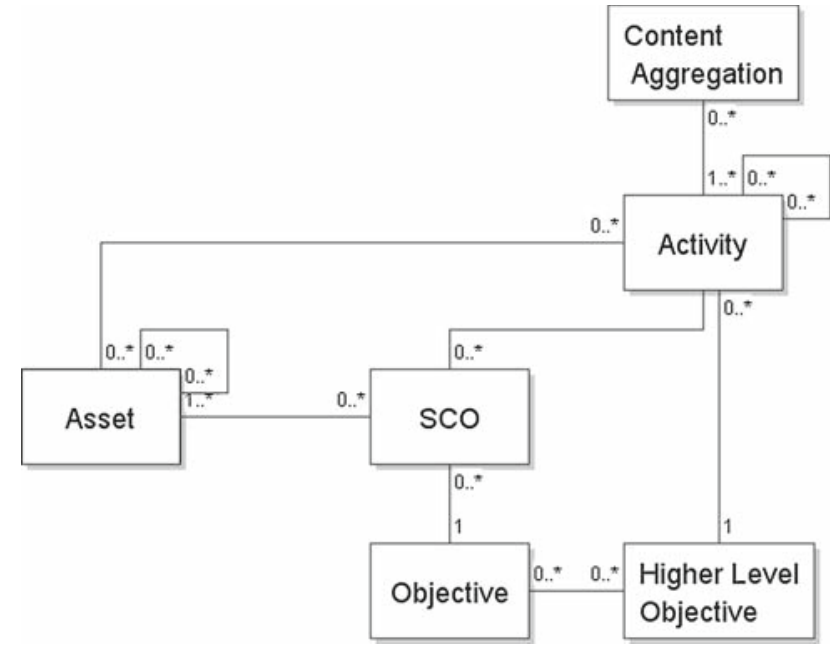

Fig. 4 UML representation of the SCORM content model

SCORM assets are raw data and media elements and information objects in the Learnativity model. SCOs are selfcontained learning objects or learning components that meet additional technical requirements needed for interoperability with learning delivery platforms. To improve reusability, an SCO should be independent of its learning context. For example, an SCO could be reused in different learning experiences to fulfill different learning objectives.

An activity aggregates SCOs and assets to form a higher level unit of instruction that fulfills higher level learning objectives. In the Learnativity content model, an activity could be an aggregate assembly. An activity contained in a Spanish course can, for instance, deal with the order of adjectives. Examples of SCOs included in the lesson are an explanation of the grammar, a practical exercise and a revision of the previously learned concepts [33]. Text, audio and video fragments contained in the SCOs are the assets.

The Spanish course can be represented in an SCORM content aggregation, containing the assets, SCOs, activities, information on the order in which these should be delivered 


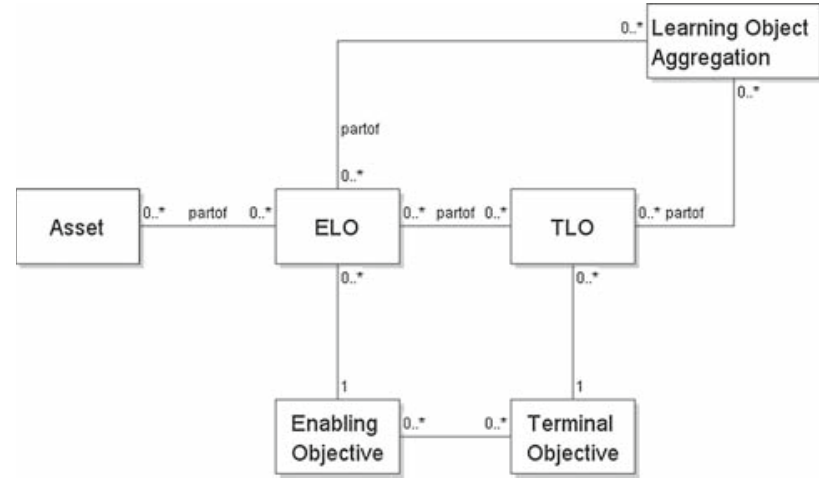

Fig. 5 UML representation of the Navy content model

and metadata about the entire aggregation and its individual components. SCORM uses a technical specification developed by the IMS Global Learning Consortium to define the format for content aggregations [19].

One of the aims of SCORM was to enable an "object based" economy for learning objects that could be shared and reused across the Department of Defense (DoD). According to a February 2006 ADL survey of SCORM content within the services, the Army Training Support Center has 161 SCORM conformant courses and 152 under development, the Army Defense Language Institute has 1,230 SCORM conformant lessons in 12 languages and 576 under development, the Navy has an estimated 442 SCORM conformant courses and 330 under development, and the Air Force has 168 SCORM conformant courses [5].

\subsection{Navy content model (NCOM)}

The Navy has refined the SCORM content model, providing more specific content definitions for granularity levels that are identified as critical for the Navy Interactive Learning Environment [28]. As the model builds upon SCORM, Navy content is SCORM compliant.

The Navy content model distinguishes between learning object aggregations, terminal learning objects (TLOs), enabling learning objects (ELOs), and assets (see Fig. 5):

1. A learning object aggregation is the top-level grouping of related content, containing TLOs and ELOs.

2. A TLO is an aggregation of one or more ELOs. A TLO satisfies one terminal objective and correlates to an SCORM activity. Terminal learning objectives are typically associated with lessons.

3. An ELO is an aggregation of one or more assets. An ELO satisfies one enabling objective and correlates to an SCORM SCO. Examples include illustrations and exercises.
Table 1 Relationship between the SCORM and NCOM hierarchy [28]

\begin{tabular}{ll}
\hline SCORM & NCOM \\
\hline Content aggregation & Learning object aggregation \\
Activity & Terminal learning object (TLO) \\
Sharable content object (SCO) & Enabling learning object (ELO) \\
Asset (with metadata) & Asset \\
\hline
\end{tabular}

4. An asset is a single text element or a single media element (e.g. an assessment object, a video, and other data elements).

A terminal objective is a major objective for a topic or task, describing the overall learning outcome. An enabling objective supports a terminal objective. Such an objective describes specific behaviors (single activities) that must be learned or performed.

The Navy content model uses SCORM as its foundation. Table 1 presents the relationship between the SCORM and NCOM hierarchy. NCOM correlates a single enabling objective to an SCO and a single terminal objective to an SCORM activity. ELO and TLO content is thus more restrictive.

\subsection{Cisco RLO/RIO model}

Cisco Systems, Inc. [3] has also adopted an object-based strategy for developing and delivering learning content. Cisco defines lessons as reusable learning objects (RLOs) and topics, of the lesson, as reusable information objects (RIOs).

Reusable information objects relate to a single learning objective and contain content, practice, and assessment items. Cisco further classifies each RIO as a concept, fact, procedure, process, or principle. Content items are classified as a definition, example, review, next steps, analogy, topology illustration, block diagrams, additional resources, cycle charts, instructor notes, introduction, principle statement, illustration, importance, outline, fact list, objectives, nonexample, table, job-based scenario, prerequisites, guideline, procedure table, decision table, demonstration, staged table, or combined table.

To build a lesson or RLO, five to nine RIOs are grouped together with an overview and summary (see Fig. 6).

The RLO-RIO strategy provides detailed guidelines to build RLOs and RIOs. For RIO types, and RLO overviews and summaries, the guidelines describe which content items are required and which may be used optionally (see Table 2).

An RIO can function as an independent learning component that can be called up by a learner who needs a specific piece of information. Or a learner can summon an RLO for a more in-depth learning experience. RLOs can be sequenced to create a course on a particular subject. And RIOs can be 


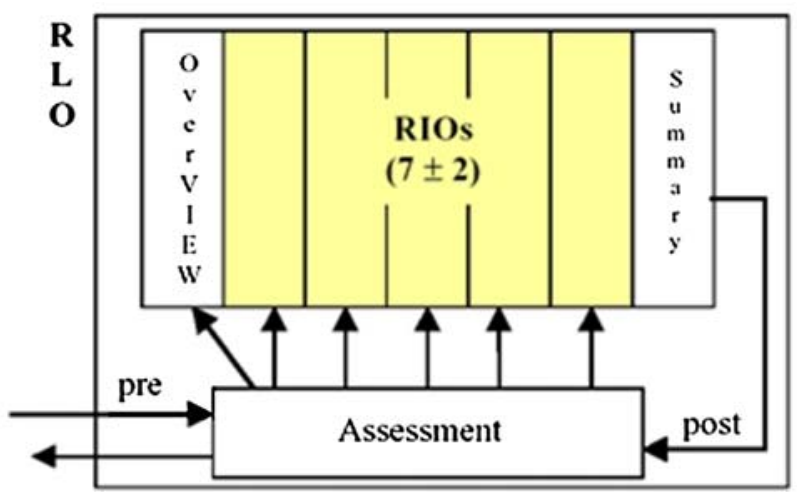

Fig. 6 The RLO and RIO structure [3]

combined together to build custom RLOs that meet the needs of individual learners [40].

When learners want to take a "lesson" or reference a "job aid", they request the raw items that make up the RLO and RIO from the digital library. Format and style sheets are then applied to the objects as they are packaged and delivered to the learner's Web browser. Because RLOs and RIOs are stored free of format and style, they can be packaged using style sheets and templates specific for instructor-led training delivery.

The Cisco model is grounded in the learning object thinking of Merrill [26] and Clark [9]. RIO and RLO classifications and guidelines for their construction are based on the structured writing methodology developed by Horn [18].

An RIO correlates to an NETg topic, an SCORM SCO, and an NCOM ELO. Content items relate to NCOM and SCORM assets and both raw data and media elements and information objects in Learnativity. An RLO correlates to Learnativity aggregate assemblies and NETg lessons. RLOs can be combined to form units and courses.

\section{6 dLCMS component model}

The dynamic learning content management system (dLCMS) project [35] aims to provide a modularization strategy combined with structured markup to enhance the reusability of learning content.

A component model is included that defines three aggregation levels (see Fig. 7):

1. Assets are media elements, such as images, videos, animations, or simulations. They are binary data objects, which cannot easily be divided into smaller components. They contain pictorial or auditory information, which can be static (image and graph) or dynamic (video, audio and animation).

2. Content elements are defined as small, modular pieces of learning content, which: (1) serve as basic building blocks of learning content, (2) can be aggregated into larger, didactically sound learning units, (3) are selfcontained, (4) are based on a single didactic content type, (5) are reusable in multiple instructional contexts, and (6) may contain assets. Examples include exercises, experiments, questionnaires and summaries.

3. A learning unit is defined as an aggregation of content elements, which is presented to the learner. Typically, a learning unit serves as an online lesson and may be used to teach several learning objectives. A learning unit provides a way to define a chapter-like, hierarchical structure of nodes. Each node will be associated with a content element through reference. The content elements are not copied into the learning unit, but are referenced by links. The component model does not define any further levels for the aggregation of learning units.

The dLCMS model defines a set of content elements categories that are related to Gagné's nine instructional events (see Table 3).

The content categories are based on the classification of Ballstaedt ${ }^{1}$ [2], the vocabulary of the LOM learning resource type $^{2}$ [12] and ContentModule types of LMML $^{3}$ (see Sect. 3.9) [39]. Literature is added to the classification.

The dLCMS model provides a well-defined hierarchy of learning object content: Assets are assembled into content elements and content elements are assembled into learning

Table 2 Overview of content items to be used for RIO types, RLO overview and RLO summary ([35]; (r) = required, (o) = optional)

\begin{tabular}{ll}
\hline RLO-RIO type & Content items \\
\hline RLO overview & Introduction (r), importance (r), objectives (r), prerequisites (r), scenario (o), outline (r) \\
RLO summary & Review (r), next steps (o), additional resources (o) \\
Concept RIO & Introduction (r), facts (o), definition (r), example (r), non-example (o), analogy (o), instructor notes (o) \\
Fact RIO & Introduction (r), facts (r), instructor notes (o) \\
Procedure RIO & Introduction (r), facts (o), procedure table (r), decision table (r), combined table (r), demonstration (o), instructor notes (o) \\
Process RIO & Introduction (r), facts (o), staged table (r), block diagrams (r), cycle charts (r), instructor notes (o) \\
Principle RIO & Introduction (r), facts (o), principle statement (o), guidelines (r), example (r), non-example (o), analogy (o), instructor notes (o)
\end{tabular}




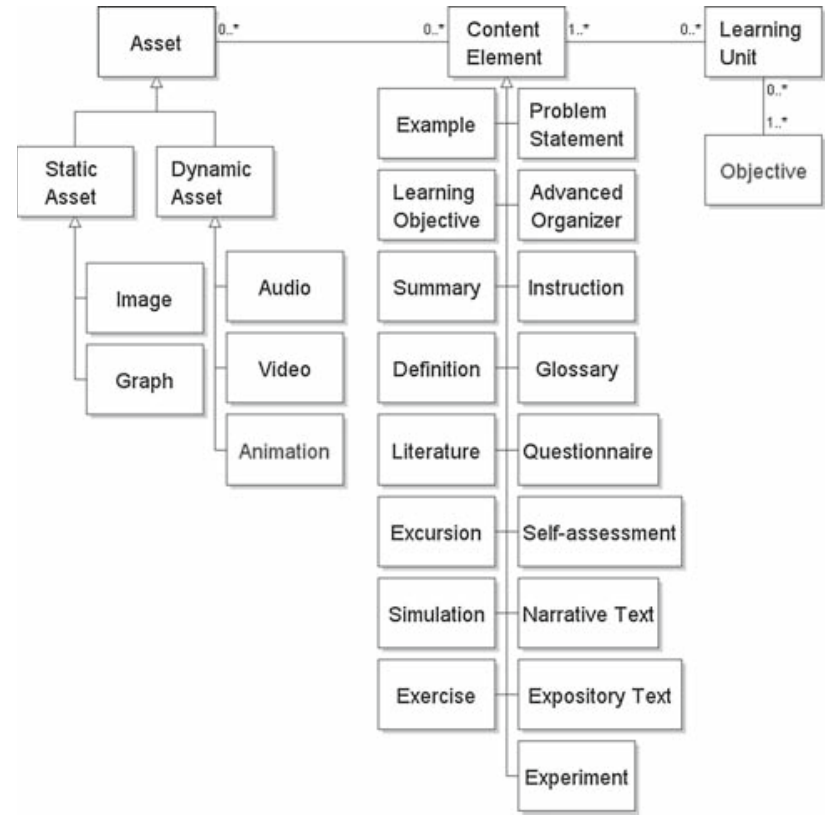

Fig. 7 UML representation of the dLCMS component model

units. Learning units may be of any size and may be used for multiple learning objectives. dLCMS does not define a learning object level that relates to a single learning objective.

The model has been developed for academic purposes. A prototype demonstrates how to handle and process modular learning content that is compliant to the dLCMS model. The implementation supports learning object authoring, storage, assembly and linking, and publishing and export functionalities.

\subsection{New economy didactical model}

Another content model developed for academic environments is the new economy didactical model [24], developed in the context of the New Economy research project, which is supported by the German Federal Ministry for Education and
Research. The aim of the project is the creation of new curricula and the development of interactive multimedia-based material for online and blended learning MBA studies. The project partners belong to seven German Universities and research institutes.

The model defines eight component types, as shown in Fig. 8:

1. An information object is defined as a small learning object, without complex logical structures, which sums up physical media (picture, video, and text) to didactically appropriate units.

2. A learning component is defined as a small learning object that combines a small number of information objects, to form one of the following features: motivation, basic knowledge or theory, example, exercise, references, further material, open questions, problems, and virtual laboratory.

3. A learning module is defined as a logical structure with a didactic aim, consisting of individual learning components. A learning module is related to a Cisco RLO or lesson.

4. A learning unit is defined as a structure designed to mediate complex content. A learning unit combines learning modules and learning components. An example is a case study containing three learning modules, combined with a virtual laboratory.

5. A course combines learning modules and learning units and can be part of a curriculum.

6. A curriculum is a composition of courses and learning units according to one or more academic specifications.

7. A learning path is a structure consisting of learning modules and learning units that can be individually adjusted to the learner.

8. A sequence is defined as a result of individual research within different digital libraries, to extend personal knowledge. It is part of the informal, but organized, learning procedure.

Table 3 Classification of didactic content types and their possible relations to Gagné's nine instructional events [35]

\begin{tabular}{ll}
\hline Instructional event & Related didactic content type \\
\hline Gaining attention & Example $^{13}$, problem statement $^{2}$ \\
Informing learners of the objective & Learning objective $^{1}$ \\
Stimulating recall of prior learning & Advanced organizer $^{1}$ \\
Presenting the stimulus & Expository text $^{1}$, definition $^{3}$, narrative text $^{12}$, instruction $^{1}$ \\
Providing learner guidance & Example $^{13}$, excursion $^{1}$, glossary $^{1}$, literature, experiment $^{2}$ \\
Eliciting performance & Exercise $^{123}$, self-assessment $^{2}$, simulation $^{2}$ \\
Providing feedback & (Feedback of self-assessment and simulations) \\
Assessing performance & Questionnaire \\
Enhancing retention and transfer & Summary \\
\hline
\end{tabular}




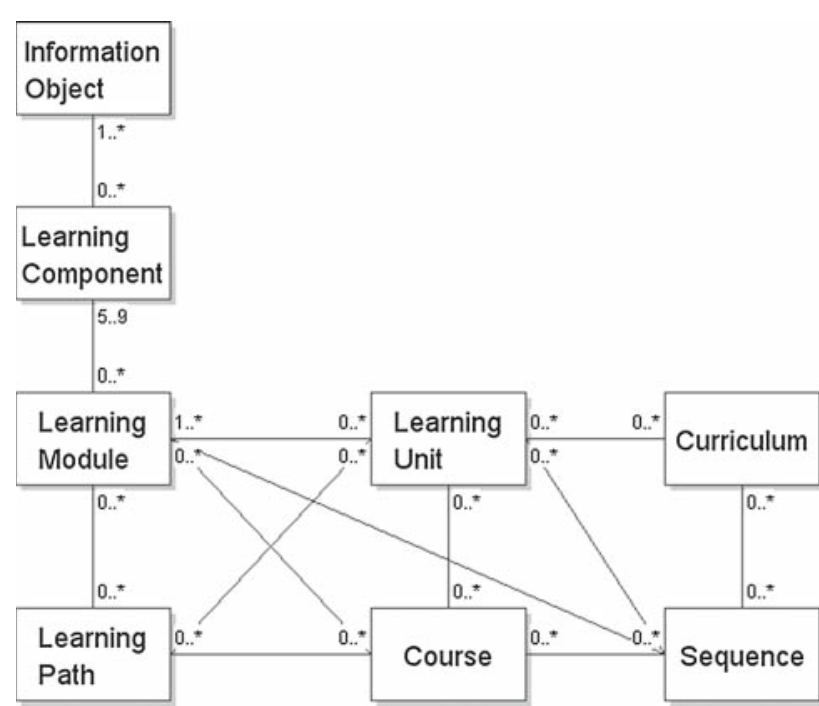

Fig. 8 UML representation of the new economy didactical model

In addition, the following characteristics are defined (see Table 4):

1. Number of combined elements describes the number of individual elements, such as video clips, pictures, or texts that are combined.

2. Type of the combined objects describes types of the learning objects, which can be combined, to form this learning object.

3. Relationship logical structure/contents: describes the portion of logical structures in relation to contentwise elements.

4. Possible didactical learning model manufactures the connection between learning object and learning theory.

5. Reusability in other learning objects describes the possibility of reuse within other learning objects.

6. Reusability in other contexts describes the possibility of the use of learning objects in other domains.

From a content perspective, six aggregation levels are defined. Learning path and sequence are pure structural elements. According to the authors of the model, an information object correlates to a Learnativity information object, a learning component to a Cisco RIO and a learning module to a Cisco RLO.

The defined characteristics derive from the work of Wiley [45]. The classifications are based on the didactical concept of problem based learning.

The new economy project is the conceptual design and implementation of a multimedia-based curriculum for online classes regarding new economy in the fields of economics, media and communications as well as computer sciences. Modules of the curriculum should be established in high profile teaching as well as being available for workshops and for

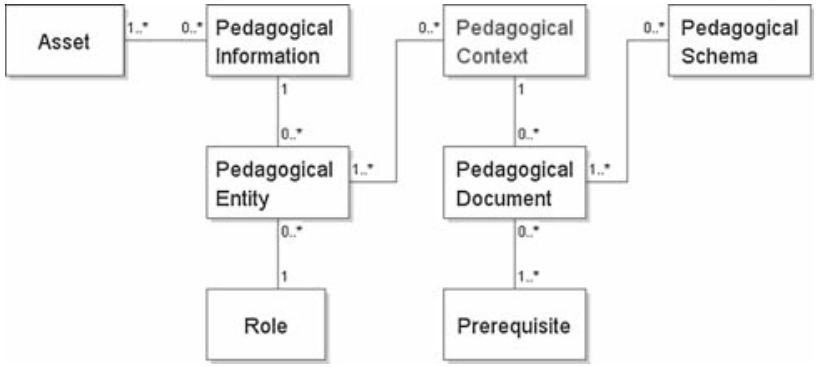

Fig. 9 UML representation of the semantic learning model

distance learning. Integration of the program into regular lectures is intended.

\subsection{Semantic learning model (SLM)}

The semantic learning model is aimed at supporting decomposition of learning objects and has been developed for academic purposes [15].

The model is illustrated in Fig. 9 and defines under six categories:

1. The lowest granularity level is an asset. Assets can be pictures, illustrations, diagrams, audio and video files, animations, and text fragments.

2. Pedagogical information is defined as "a group of assets that express the same meaning". An example is a figure associated with a comment.

3. A pedagogical entity is defined as "a pedagogical information component, associated with a pedagogical role". Four roles are defined: concept, argument, solved problem and simple text.

4. A pedagogical context is defined as "a semantic structure (or network) in which pedagogical entities are grouped".

5. A pedagogical document contains a pedagogical context, associated with prerequisites.

6. Many pedagogical documents are grouped to make a curriculum. This group is called pedagogical schema

From a content perspective, four aggregation levels are defined. A pedagogical entity and a pedagogical document represent respectively a single pedagogical information component and a single pedagogical context. Pedagogical roles and prerequisites are added as metadata.

According to the authors of the model, an asset correlates to a Learnativity raw data and media element, a pedagogical information component to a Learnativity information object, a pedagogical entity to a Learnativity application object, a pedagogical context to a Learnativity aggregate assembly and a pedagogical document to a Learnativity collection. 


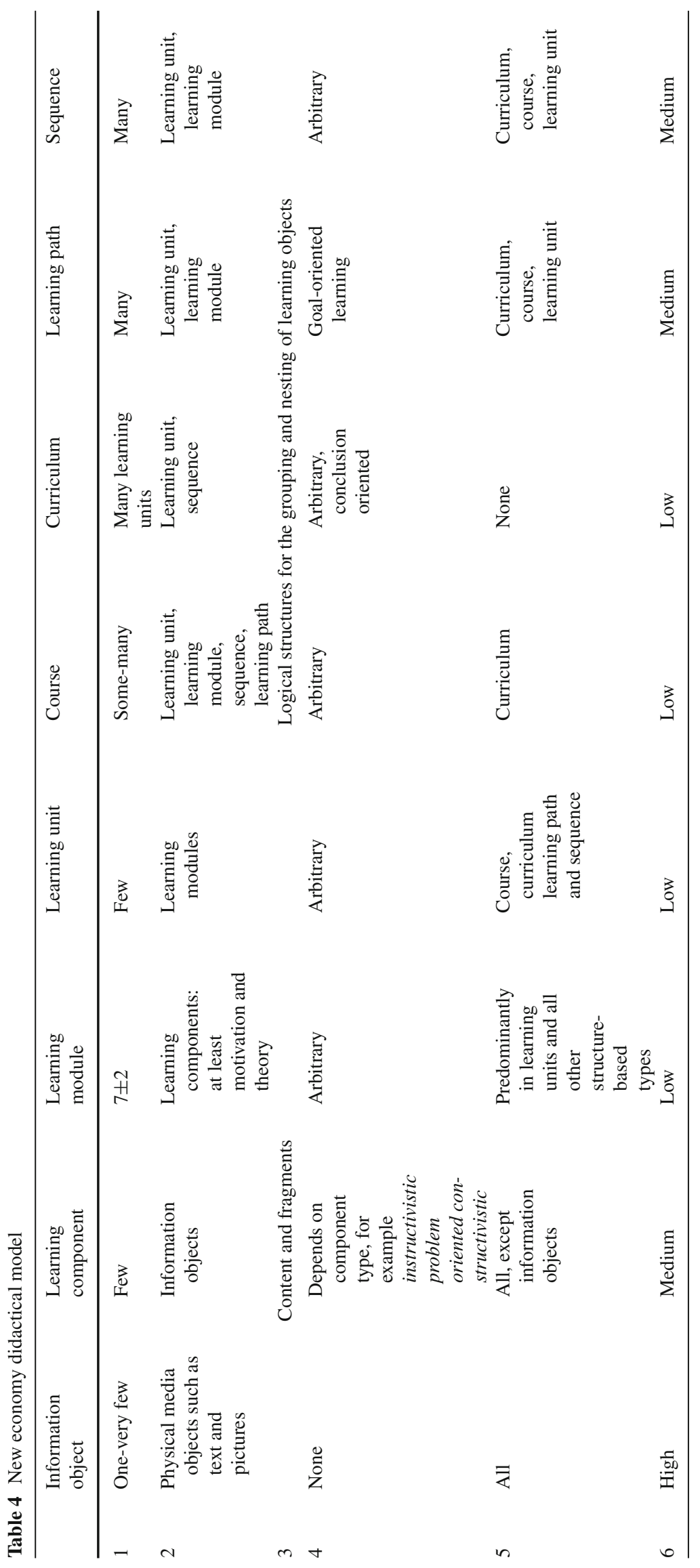




\subsection{PaKMaS}

The Passauer knowledge management system (PaKMaS) [39] is an hypermedia content management system that provides search, editing, evaluation and exchange facilities for learning material for teachers and students.

A content model is defined that distinguishes between media objects, content modules, and structuring modules (see Fig. 10).

- Media objects are defined at the lowest granularity level. Such elements are classified as text, audio, animations and images.

- Content modules contain media objects and are classified as motivations, definitions, remarks, paragraphs, examples, exercises, and illustrations. Their content can be structured as lists or tables.

- Content modules are grouped into structuring modules that realize multiple teaching strategies. Their content is structured into sections and collections. Structuring modules are categorized into GuidedTours, collections, glossaries and indexes.

The model defines its own classification. Some of the concepts can be found in structured writing (definition, remark, and example) [18], the classification of Ballstaedt (example and glossary) [2] and the vocabulary of the learning resource type in IEEE LOM (exercise and index) [12].

A knowledge management system has been developed that provides search, editing, evaluation and exchange facilities for learning objects. Content modules and structuring modules are stored in LMML (learning material markup language) documents [39] or CMI software components. The model is used in university education, further education and company training.

\section{Comparative analysis}

Table 5 aligns content model aggregation levels. The NETg learning object model consists of four levels. The model specifies three levels for the aggregation of learning objects, or topics, but provides only an abstract definition of their content, as no learning object components are defined.

The other models define learning object components in one or two levels. SCORM, NCOM, Cisco, and new economy define one level. Cisco describes the content types of this level conceptually, but no specification is given from a technical point of view [35]. The models seem to agree that this level consists of individual, reusable, resources. In SCORM, assets can aggregate other assets too.

The Learnativity, SLM, PaKMaS and dLCMS models define a second level for learning object components that

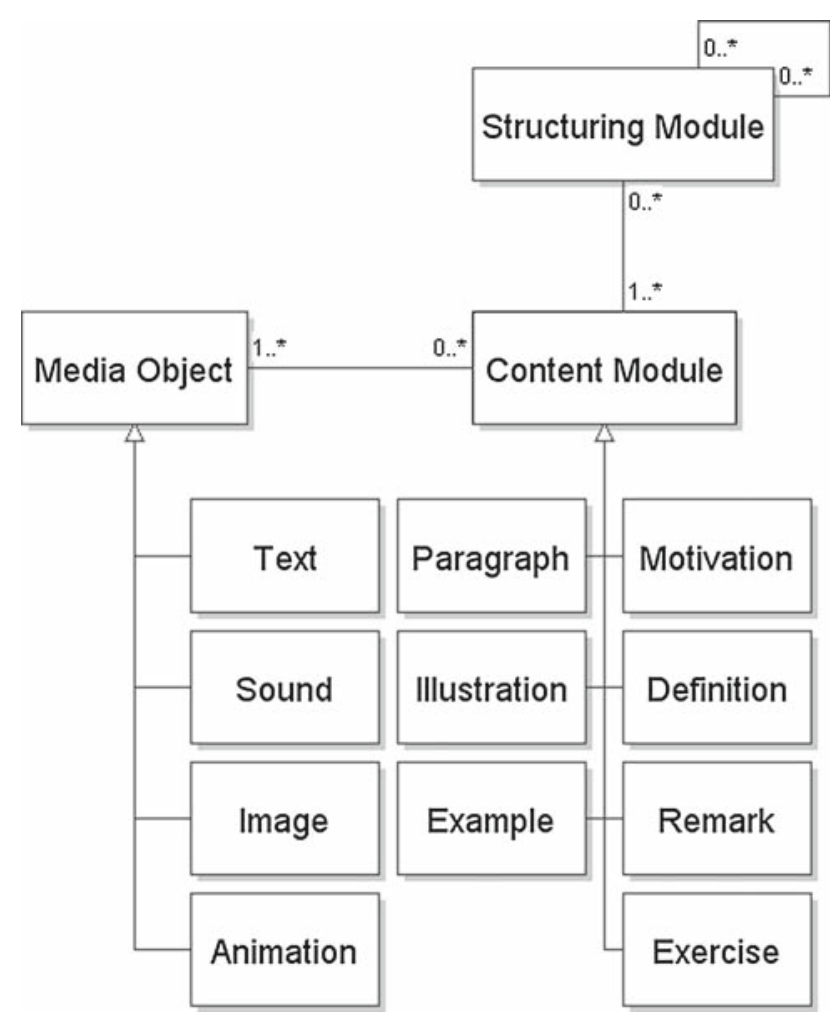

Fig. 10 UML representation of the PaKMaS model

aggregates first level components. The models define this component level as an aggregation of assets that focus on a single piece of information, but not necessarily relating to a specific learning objective.

The dLCMS and PaKMaS models define learning objects as aggregations that relate to one or more learning objectives. The other content models define learning objects consistently as content aggregations that relate to a single learning objective. These models define aggregations of learning objects into an additional level that relates to multiple or larger learning objectives. Lessons are commonly associated with this aggregation level. Learnativity, NCOM, and SCORM define a third aggregation level for learning objects, representing courses and curricula. Finally, the NETg and new economy models define a content hierarchy for this granularity level (unit, course and learning unit, course, and curriculum, respectively).

\section{Ontology-based approach for content model interoperability}

Learning object definitions provided by the reviewed content models vary considerably:

- Granularity is defined in three to six levels, 
- different terms are used to refer to the same concept: a Learnativity information object is, for instance, equivalent to a PaKMaS content module,

- different classifications are used: derived from structured writing [18], LOM [12] and the classification of Ballstaedt [2], and

- different constraints on content levels are imposed. For example, Cisco defines learning object content strictly as an aggregation of $7 \pm 2$ RIOs.

The interoperation of learning content is essential for enabling a learning object economy characterized by searchable digital libraries of reusable learning objects that can be exchanged and reused across various learning systems. Ontologies offer a great potential in enabling such interoperability. Contents, essential properties and relationships can be expressed and mappings or equivalences can be defined between models. In [6], a method is introduced to integrate data using ontologies. The method is illustrated in Fig. 11 and has three main stages:

- building a global ontology that covers the content models,

- building local content model ontologies, and

- defining mappings between the models.

The rest of this section briefly explains the method and how we used it for content model integration.

\subsection{First stage: building the global ontology}

This stage contains three main steps: analysis of models, search for terms and defining the global model. The analysis has been presented in Sects. 3 and 4. The global model should define the different granularity levels and their interrelationships. Also content classifications defined for granularity

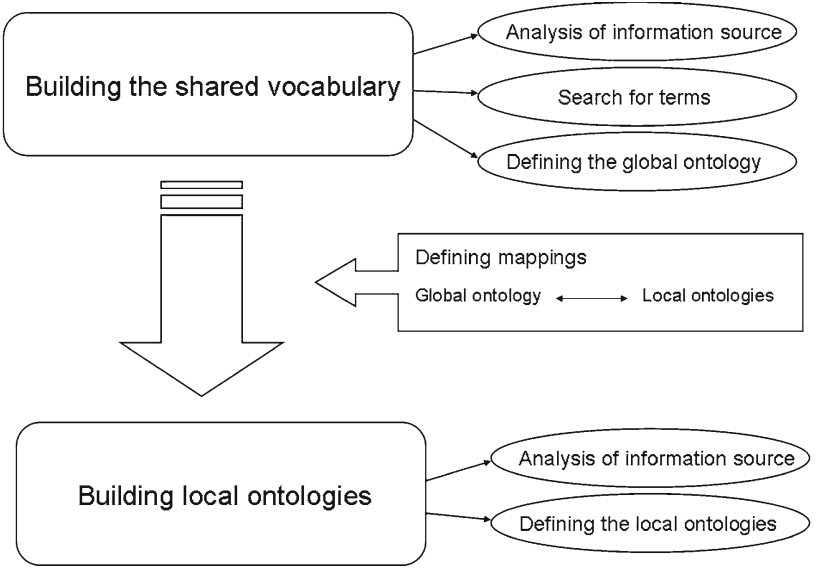

Fig. 11 Ontology construction method [6]

levels should be represented. We develop such a model in the next section.

\subsection{Second stage: building local ontologies}

In this stage, an independent analysis of each content model is made, without taking the other content models into account. An ontology is created for each content model, defining its own classes and relationships according to the specification of the model. Section 7 illustrates the development of local ontologies.

\subsection{Third stage: defining mappings}

In this stage, mappings (and relationships) are defined between the classes defined in the global ontology and classes defined in the local ontologies. This stage must solve heterogeneity problems, making connections between the two stages. Such mappings are presented in Sect. 8.

Table 5 Content model comparison

\begin{tabular}{|c|c|c|c|c|c|c|}
\hline & \multicolumn{2}{|c|}{ Learning object component } & \multicolumn{4}{|c|}{ Learning object } \\
\hline & $\mathrm{CF}$ & $\mathrm{CO}$ & Single-objective & Larger objective & LO aggre & gations \\
\hline SCORM & Asset & & $\mathrm{SCO}$ & Activity & Content aggregation & \\
\hline NETg & & & Topic & Lesson & Course & \\
\hline Learnativity & Raw media & Information object & Application object & Aggregate assembly & Collection & \\
\hline NCOM & Asset & & ELO & TLO & Learning object aggreg & tion \\
\hline Cisco & Content item & & $\mathrm{RIO}$ & RLO & & \\
\hline New economy & & Information object & Learning component & Learning module & Learning unit Course & Curriculum \\
\hline SLM & Asset & Pedagogical information & Pedagogical entity & Pedagogical context & Pedagogical document & Pedagogical schema \\
\hline PaKMaS & Media object & Content module & Structuring modules & & & \\
\hline dLCMS & Asset & Content element & Learning unit & & & \\
\hline
\end{tabular}




\section{The ALOCOM model}

A global content model should define the different granularity levels that are present in current content models and their interrelationships. We developed such a model in the ontology language OWL [4], as we use ontologies as a means to implement content model mappings.

To define granularity levels, we applied a top-down approach. Starting from the aligned content model representation presented in Table 5, we defined learning object granularity levels in a hierarchical structure. These granularity levels are presented in Sect. 6.1. Relationships between the levels are detailed in Sect. 6.2. In the next step, concept hierarchies were defined for the aggregation levels. For defining these taxonomies, we investigated different classification schemes and the extent in which they are used by the content models. The content classifications are detailed in Sect. 6.3, followed by a brief discussion on the content model creation process.

\subsection{Granularity levels}

As indicated in the aligned content model representation presented in Table 5, the distinction should be made between learning object components and learning objects. These toplevel granularity levels correspond, for instance, to SCORM assets and PaKMaS structuring modules. Both learning object components and learning objects are further subdivided to represent narrower granularity definitions of other content models. Two subclasses are defined for learning object components that correspond to the component granularity levels of Learnativity, dLCMS, PaKMaS and SLM. Three subclasses are defined for learning objects. Figure 12 present the hierarchy.

Learning object components are subdivided into:

1. Content fragments, defined as individual content components such as text, images, audio and video fragments.

2. Content objects, defined as learning object components that aggregate content fragments. Content objects focus on a single piece of information and can be used to explain a concept, illustrate a principle, or describe a process.

Learning objects are subdivided into:

1. Single-objective LOs, defined as aggregations of learning object components that relate to a single learning objective. Examples are concepts, facts, principles, processes and procedures.

2. Larger objective LOs aggregate single-objective LOs and relate to larger learning objectives. Examples are chapters and lessons.
3. LO aggregations represent the largest granularity level for learning objects. Units, courses and curricula are defined as sub-classes of LO aggregations. Such hierarchies are, for instances, represented in the NETg and new economy content models.

How these aggregation layers correspond to granularity levels of the reviewed content models is detailed in Sect. 8.

\subsection{Relationships}

Aggregation relationships are defined in the form of "hasPart" and "isPartOf" properties. Content fragments are aggregated by content objects. Both content fragments and content objects are aggregated by learning objects and learning objects also aggregate other learning objects. Singleobjective LOs are aggregated by larger objective LOs and both single and larger objective LOs are aggregated by LOaggregations.

\subsection{Content classifications}

Classifications have been defined for content fragments, content objects and single-objective LOs. The classifications are detailed in the rest of this section.

\subsubsection{Content fragments}

The ALOCOM model defines content fragments at the lowest level of granularity. Content fragments are uncombined content components that are digital representations of media. These components are commonly classified as [29]:

- Text

- Graphic: examples are photographs, diagrams, graphs, symbols, maps, pictographs, timelines, charts, etc.

- Animation

- Video

- Audio.

None of the content models define a complete classification for content fragments. Instead, the component types are used as examples.

\subsubsection{Content objects}

Content models use (part of) the following classification schemes to define content objects:

- the vocabulary of the learning resource type in IEEE LOM [12],

- the classification of Ballstaedt [2], and

- structured writing [18]. 
Fig. 12 The ALOCOM aggregation levels

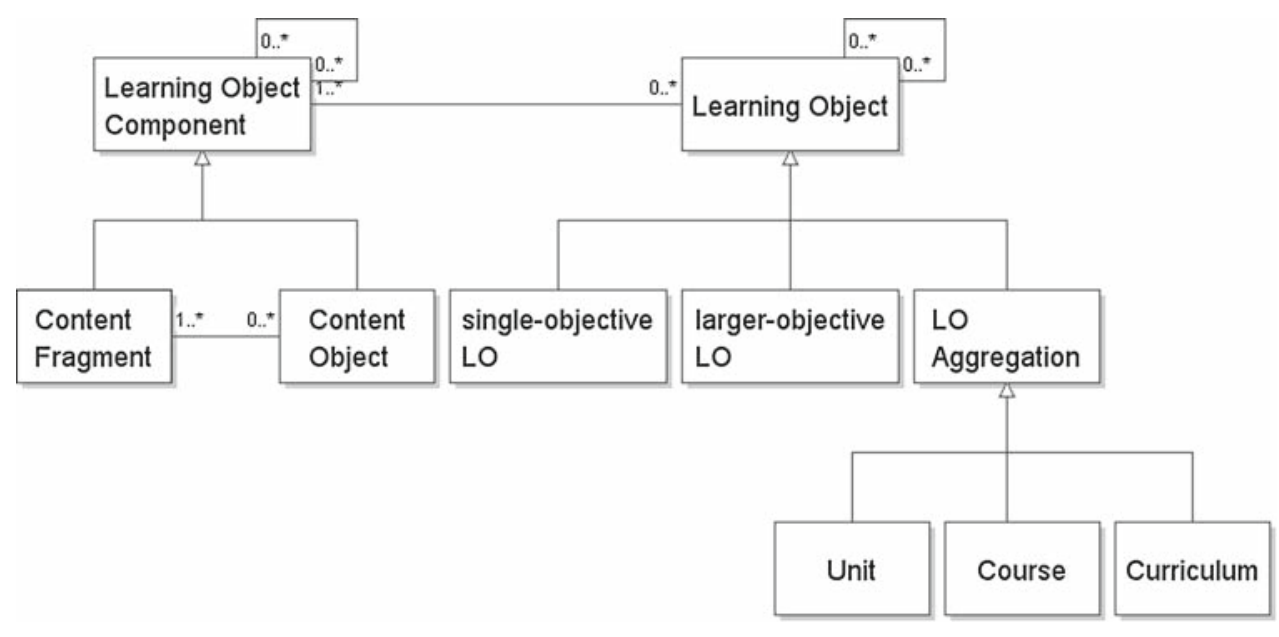

Cisco, dLCMS, PaKMaS, new economy and Learnativity use part of this structured writing classification. Cisco uses a subset that contains 29 of the 200 defined component types: overview, summary, definition, example, review, analogy, topology illustration, next steps, block diagrams, additional resources, cycle charts, instructor notes, introduction, principle statement, illustration, importance, outline, fact list, objectives, non-example, table, job-based scenario, prerequisites, guideline, procedure table, decision table, demonstration, staged table, and combined table. The new economy model uses examples, references, and further material that relates to additional resources. dLCMS uses objectives, summaries, examples and definitions, and PaKMaS uses definitions, remarks, examples, and illustrations. Learnativity uses the classification to exemplify information objects, but no precise specification of component types suitable for defining learning content is provided.

The IEEE Learning Object Metadata Standard [12] defines a vocabulary for learning resources types that is partially used by the dLCMS, PaKMaS, Learnativity and new economy content models. Exercises, simulations, questionnaires, narrative text, experiments, problem statements and selfassessments are used by the dLCMS content model. Exercises can be found in PaKMaS and exercises and simulations can be found in the Learnativity model. Finally, problem statements, simulations and exercises can be found in the new economy model.

The classification of Ballsteadt is used by the dLCMS model. The new economy content model uses the term theory or basic knowledge to denote advanced organizers. Finally, the following concepts are used by the dLCMS and/or new economy content models that are not represented in the structured writing, Ballstaedt or LOM learning resource type classifications: motivation, open question, paragraph, and literature. The content object classification defined in the global content model represents the union of these used concepts, and is shown in Fig. 13. The combination of these elements is briefly discussed in Sect. 6.4.

\subsubsection{Learning objects}

Single-objective LOs are commonly classified as concepts, facts, principles, processes and procedures. These content types derive from the work of Horn [16], who defined seven information types: concept, fact, classification, structure, principle, procedure and process. None of the content models explicitly define structure and classification as learning object types.

Current content models do not classify larger objective learning objects. The only examples that can be found are lessons and chapters. Hierarchies for LO aggregations, such as unit, course, curriculum, are defined by some models.

\subsection{Discussion}

Constructing a global content model that covers existing content models is a complex task, as different interpretations of learning object granularity need to be integrated. Some content models define few granularity levels, each covering a wide variety of learning objects, while others employ narrow granularity definitions in multiple layers.

To combine both broad and narrow approaches, we defined a hierarchical granularity structure. The aim of such structure is to enable one-to-one content model mappings. A content model that distinguishes between single and larger objective learning objects can find corresponding classes at the second level. Content models that employ a single granularity definition for learning objects can map these objects to the top-level learning object class. Mapping details that validate the approach can be found in Sect. 8 .

For defining content classifications, we combined the concepts that are used by the reviewed content models. 
Fig. 13 The ALOCOM model

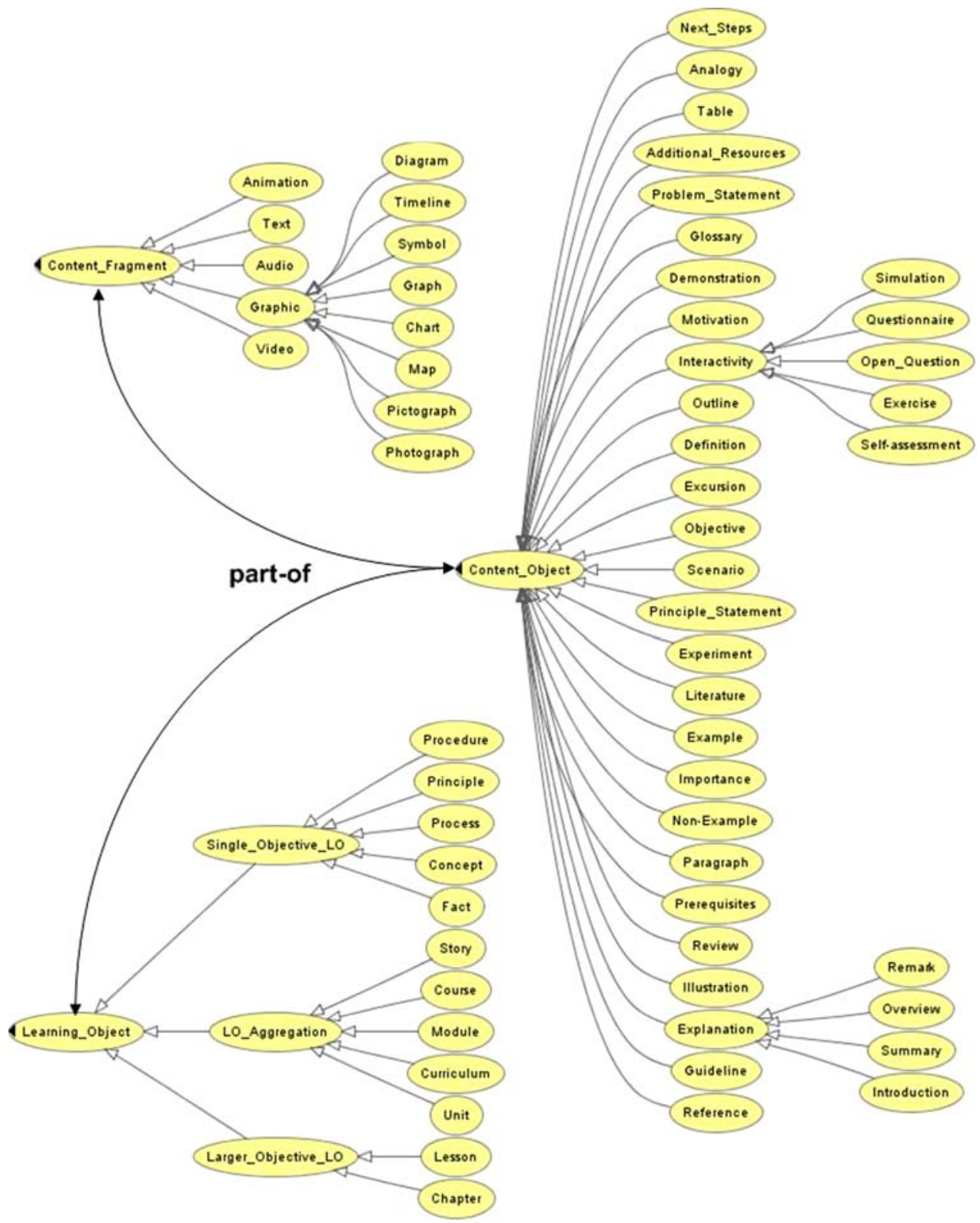

Single-objective learning objects are commonly categorized into five content types. Content objects, on the other hand, have diverse classifications that are based on structured writing, the classification of Ballsteadt and IEEE LOM. As the classifications overlap to some extent and use the same terms to denote equivalent concepts, we merged the concepts into a global taxonomy. New concepts, introduced by the dLCMS and PaKMaS models, were also added. This merged taxonomy is definitely not the only or the "perfect" classification approach. However, it is a first step in the support of a global content model for learning objects and can adequately cover existing definitions. Further research is required to determine to which extent this classification can cover learning content in every subject matter.

\section{Local ontologies}

In the second stage of the method, local ontologies are defined for each content model, representing concepts and relationships defined by the model. The local ontology of the Cisco model is detailed in this section. Other local ontologies are defined analogously. Their UML representations can be found in Sect. 3.

\subsection{The Cisco ontology}

The Cisco ontology defines Cisco components and their interrelationships. An excerpt of the UML representation of the ontology is shown in Fig. 14. Concepts, concept hierarchies 
and aggregation relationships are represented in the UML diagram, and in other UML diagrams presented throughout this paper. Constraints imposed on content components are presented in the axiom set below and are expressed in firstorder logic. The constraints indicate, for instance, that a Cisco concept should contain an introduction, definition and example, and may contain a fact list, non-example, analogy and instructor notes. Cardinality constraints are included in the UML diagrams.

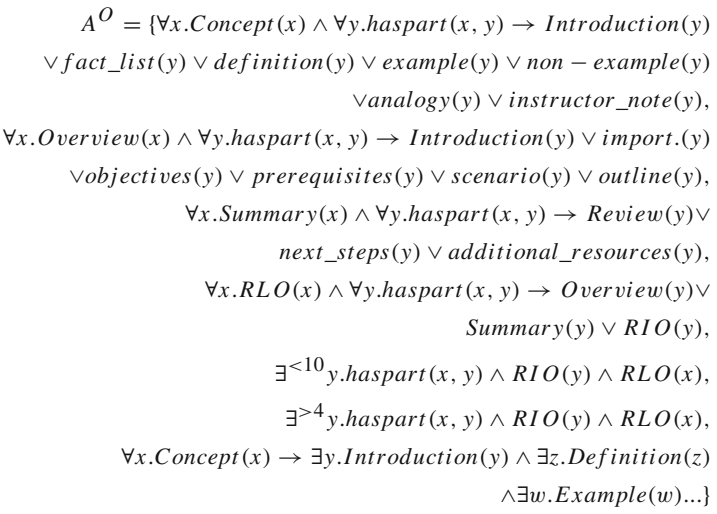

\section{Mappings}

In the last step, ontology mappings are defined between the global ALOCOM model and local content model ontologies.

Ontology mappings are often defined as: "Given two ontologies A and B, mapping one ontology with another means that for each concept in ontology A, we try to find a corresponding concept, which has the same or similar semantics, in ontology B and vice versa." [38]

Formally, an ontology mapping function can be defined as:

- map: $O_{i} 1 \rightarrow O_{i} 2$

$-\operatorname{map}\left(e_{i} 1 j 1\right)=e_{i} 2 j 2$, if $\operatorname{sim}\left(e_{i} 1 j 1, e_{i} 2 j 2\right)>t$, with $t$ being the threshold, entity $e_{i} 1 j 1$ is mapped to $e_{i} 2 j 2$

Mappings defined between the global ALOCOM ontology and local content model ontologies are bi-directional. The complete content object and learning object mappings are presented in Figs. 15 and 16. The content fragment mapping is not shown, as most content models use similar terms to denote these component types (text, audio, video, animation, etc.).

\subsection{Learning object component mappings}

Cisco content items, SCORM assets and NCOM assets are mapped to the ALOCOM LO_component class, as the granularity levels constitute both ALOCOM content fragments (e.g. block diagram and cycle chart in Cisco) and ALOCOM content_objects, such as examples, definitions, introductions and demonstrations.

Learnativity raw data and media elements, dLCMS assets, PaKMaS media objects, and SLM assets are equivalent to ALOCOM content fragments. Learnativity information objects, PaKMaS content modules, SLM pedagogical information elements, new economy information objects and dLCMS content elements are equivalent to ALOCOM content objects.

Content object subclasses are often represented with the same name. Semantically related concepts are, amongst others:

- alocom:simulation $\rightarrow$ neweconomy:virtual_laboratory

- alocom:overview $\rightarrow$ neweconomy:basic_knowledge

- alocom:overview $\rightarrow$ dlcms:advanced_organizer

_ alocom:remark $\rightarrow$ cisco:instructor_note.

\subsection{Learning object mappings}

SCORM SCOs, NETg topics, NCOM ELOs, Cisco RIOs, Learnativity application objects, and SLM pedagogical entities relate to single learning objectives and are mapped to the ALOCOM single_objective_LO class. ALOCOM single_objective_LO subclasses have equivalent Cisco (and Learnativity) classes.

According to the authors of the new economy content model, new ecomomy learning components relate to Cisco RIOs and would have to be mapped to the ALOCOM single_objective_LO class. However, if we consider the content elements that a new economy learning component constitutes (motivation, theory, example, exercise, references, further material, open questions, problems, and virtual laboratory), the elements relate to ALOCOM content_objects. To resolve the inconsistency, new economy learning components are mapped to the union of ALOCOM content_objects and single_objective_LOs.

SCORM activities, Learnativity aggregate assemblies, NCOM TLOs, Cisco RLOs, SLM pedagogical contexts and new economy learning modules represent LOs relating to several or larger objectives and are mapped to the ALOCOM larger_objective_LO class.

NCOM LO Aggregations, SLM pedagogical documents and SCORM content aggregations are semantically equivalent to ALOCOM LO_aggregations. Classifications of this top level granularity level are similar in most content models. The NETg and new economy hierarchies unit, course and unit, course, curriculum are represented in ALOCOM and are mapped to their equivalent classes. An SLM pedagogical schema is mapped to the ALOCOM curriculum class. Finally, the PaKMaS structuring module and dLCMS learning unit 
Fig. 14 UML representation of the Cisco RLO-RIO model

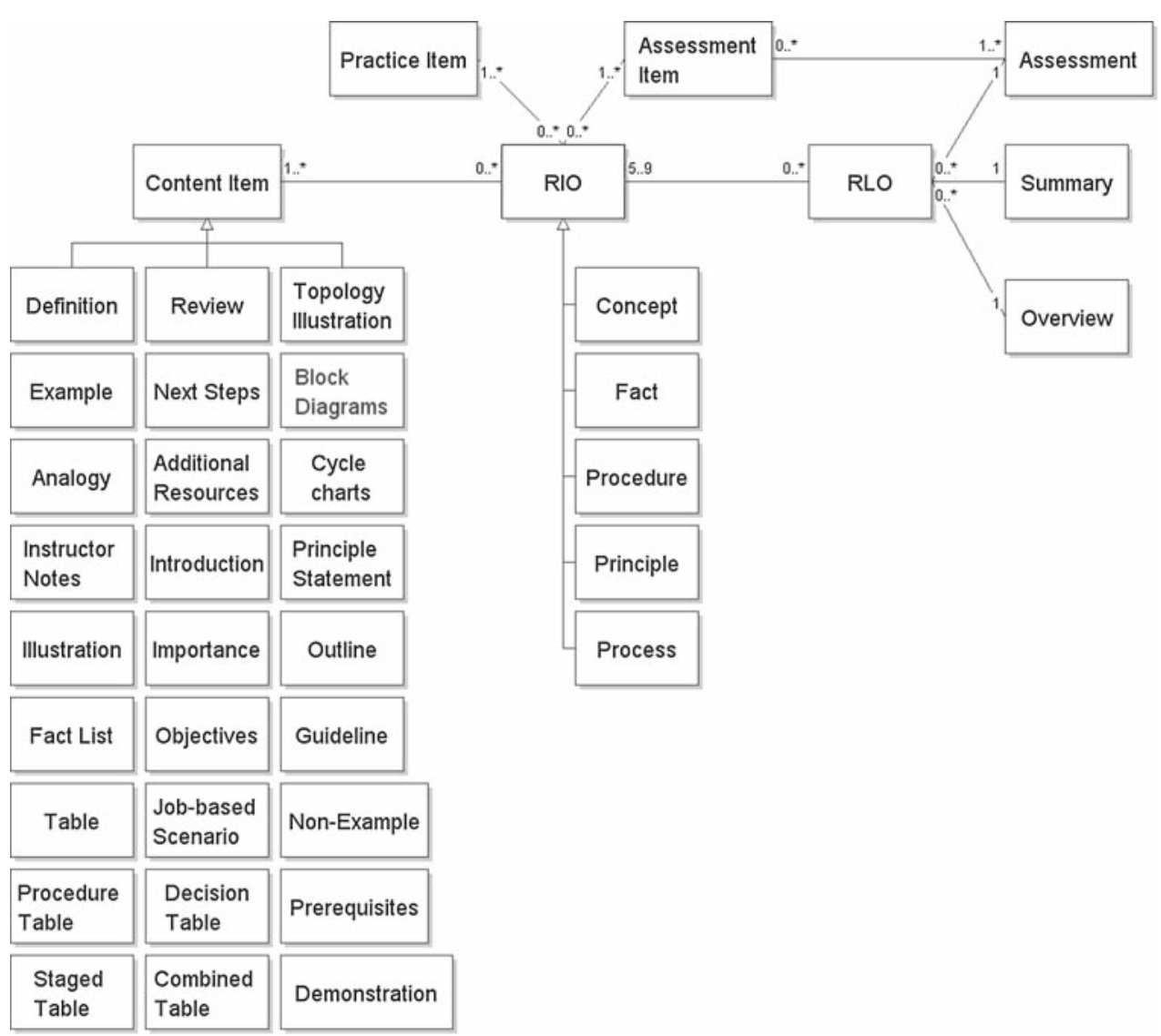

classes are mapped to the ALOCOM learning_object superclass, as no distinction is made between single and larger objective learning objects.

\subsection{Discussion}

Most content models map easily onto the ALOCOM model. The Cisco, NETg, NCOM, Learnativity, dLCMS, and PaKMaS content models provide clear granularity definitions and examples that facilitated their analysis, the construction of the global ALOCOM content model and the implementation of mappings. Some difficulties were encountered in mapping the SCORM, SLM and new economy content models:

- SCORM defines assets as its basic building blocks, SCOs as aggregations of one or more assets and activities as aggregations of one or more SCOs or assets. SCOs are intended to be subjectively small units, such that potential reuse in different learning experiences, to fulfill different learning objectives, is feasible. Activities are intended to form a higher level unit of instruction that fulfills higher level learning objectives.

On the basis of this intended use, SCORM can be mapped to ALOCOM. However, SCORM components do not have to comply with these guidelines. Strictly speaking, the only difference between an Asset and an SCO is that an SCO communicates with an LMS. SCORM claims to be neutral about the complexity of content: content aggregations or activities can range from a few lines of text to highly interactive learning resources. Applying these broad definitions, the SCORM to ALOCOM mapping might not be valid.

- The definition of content components in SLM is rather fuzzy: six aggregation levels are defined, but only four can aggregate more than one content component. Furthermore, it is unclear what is meant by the definition of a pedagogical context, i.e. "a semantic structure in which pedagogical entities are grouped". The lack of precise definitions and examples were a bottleneck in the analysis of the content model. For mapping the SLM content model, we solely relied on its relationship to the Learnativity content model as proposed by the authors.

- As indicated in Sect. 8.2, the definition of new economy learning components is somewhat contradictory. The authors define learning components as motivations, theories, examples, exercises, references, further material, open questions, problems, and virtual laboratories. In addition, they relate the component type to Cisco RIOs that constitute concepts, facts, principles, processes and procedures. To resolve the inconsistency, we mapped 
Fig. 15 Learning object component mappings

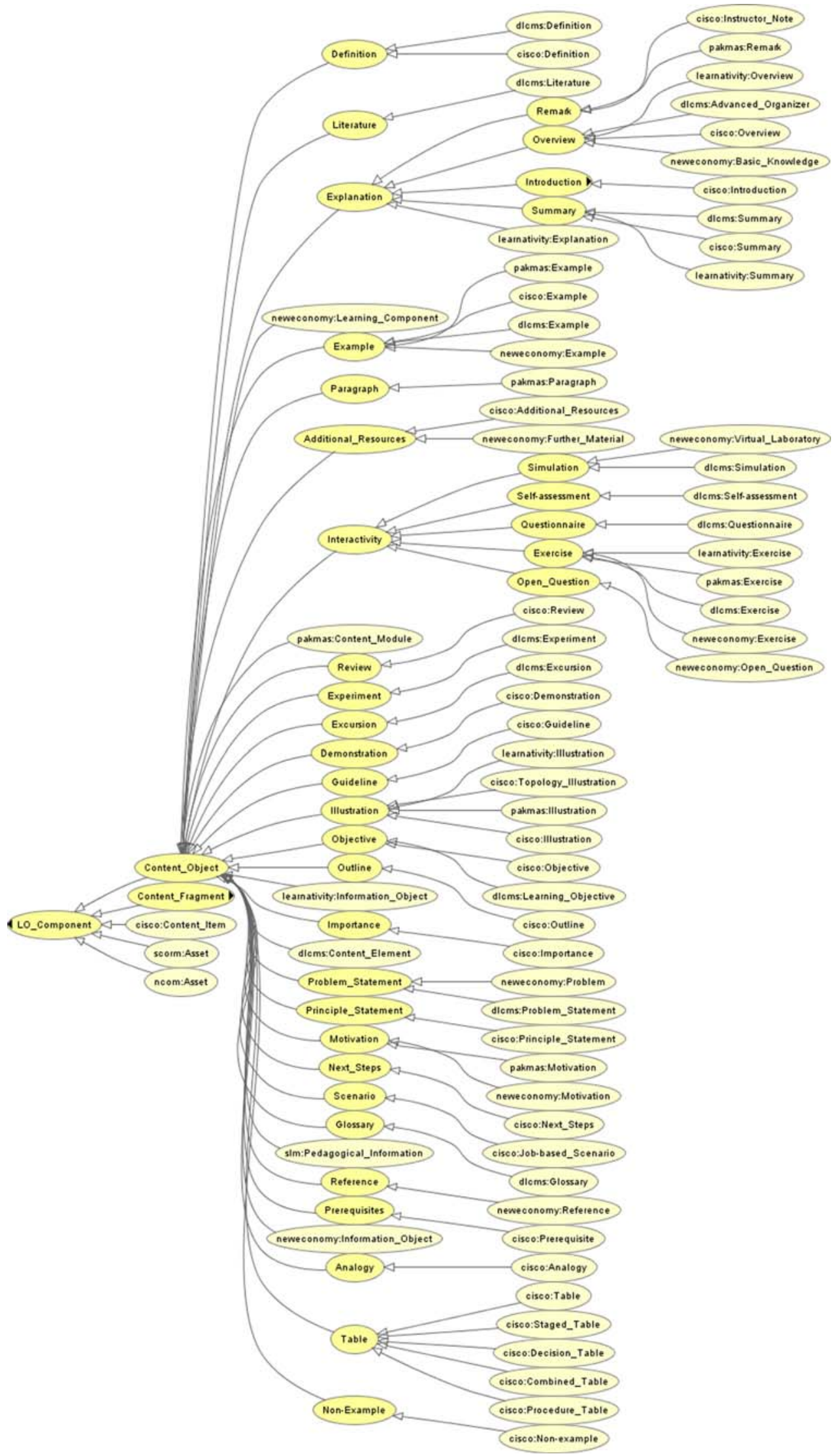


Fig. 16 Learning object mappings

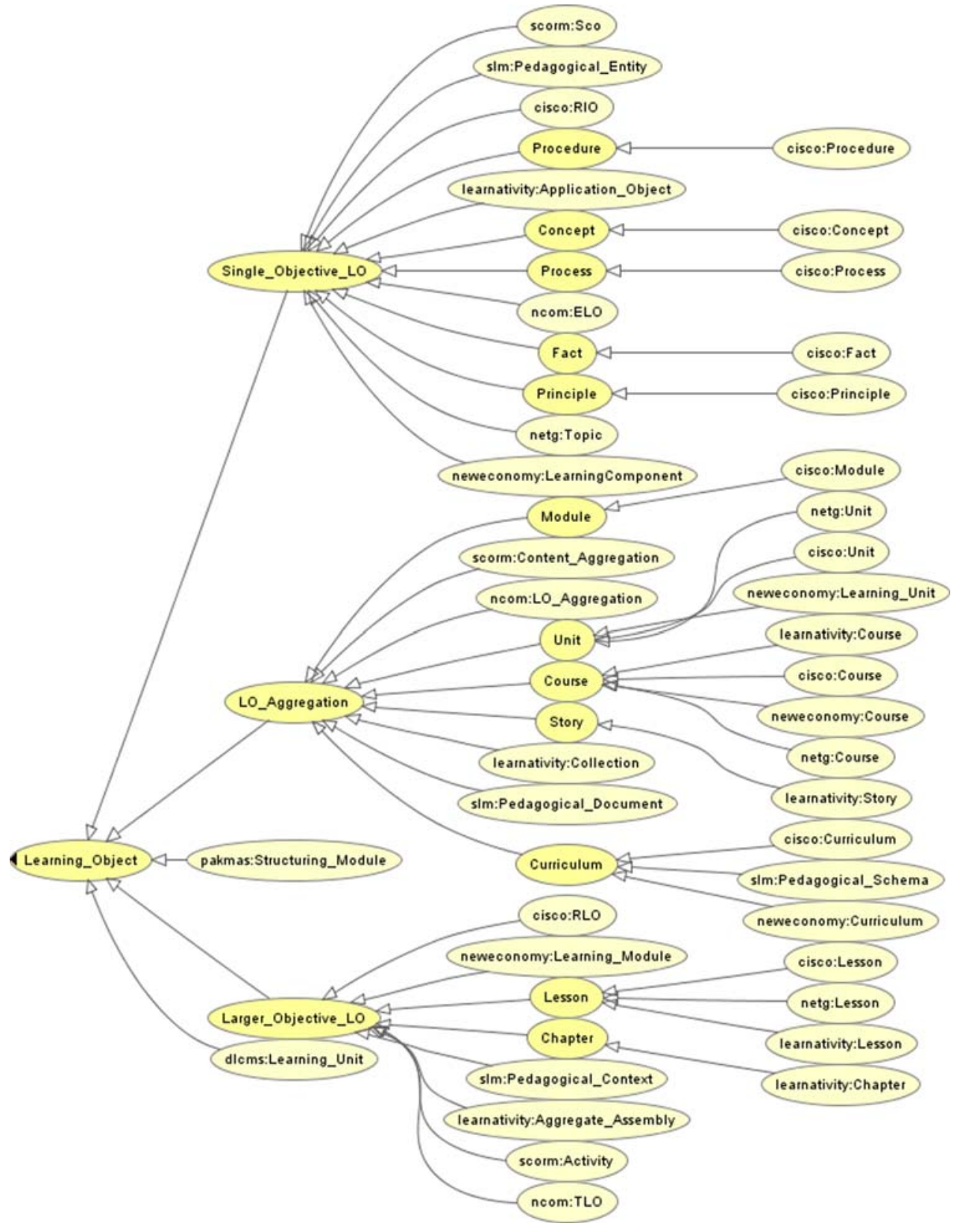

the component type to the union of ALOCOM content objects and ALOCOM single objective LOs.

\section{RAMLET}

Learning object content models define learning objects at a conceptual level, specifying component types at different levels of granularity and their interrelationships. To deliver learning objects to an LMS, many content packaging formats have been specified, such as IMS CP [19], METS [27] and MPEG-21 DIDL [21] formats. Each of them is based on the idea of a central XML file that either references or contains the content files that make up the package, embodying a structured inventory of the content of the package.

RAMLET [31] is a project that is developing a reference model for such content packaging formats and is aimed at facilitating their interoperability by enabling the interpretation of their external representations and properties. Common structural concepts and their properties are defined in the RAMLET model. For instance, each aggregation format defines a TopNode element that is the highest level of aggregation. In IMS CP, this concept is represented by a manifest element; in MPEG-21 DIDL by a container element; and in METS by a structMap element. A common structural concept TopNode is defined in the RAMLET model, and the CP 


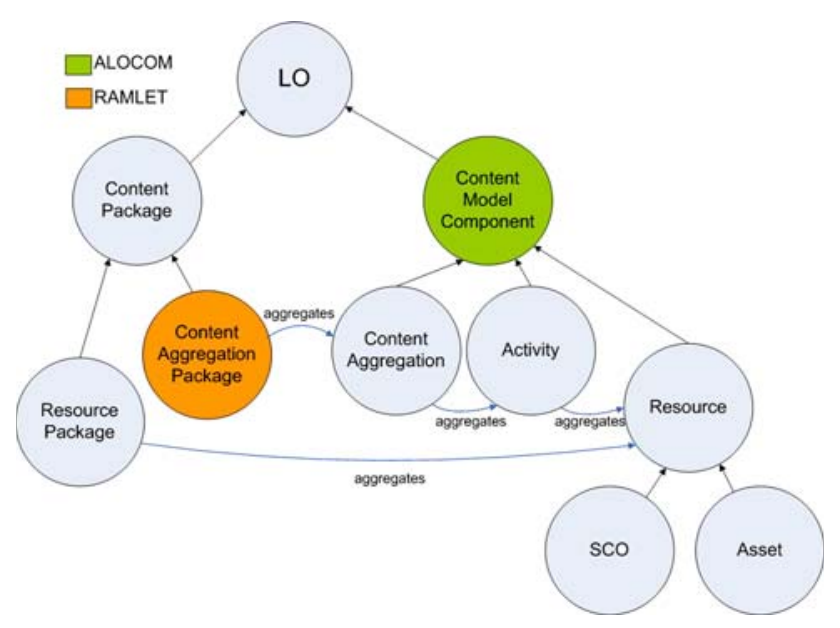

Fig. 17 RAMLET-ALOCOM relation

manifest element, the MPEG-21 DID container element and the METS StructMap element are mapped to the TopNode element in RAMLET to indicate their equality.

The RAMLET reference model provides a standard way to structure and exchange learning content, but is not concerned with relationships between the learning object components contained in the package or learning object component types [31]. For instance, a concept learning object and its components, such as introduction, definition, fact, example, non-example, analogy and note in a Cisco context, will all be represented as a resource in the RAMLET model.

Figure 17 illustrates the relation between the RAMLET and ALOCOM models in the context of SCORM. In general, ALOCOM describes the types of learning object components used in a content package and their interrelations, while RAMLET defines how to package these components to provide successful exchange from system to system.

Certain overlaps exist between the structural descriptions provided by RAMLET and the content definitions of the ALOCOM model. Both models contain a content aggregation element. In the RAMLET model, this element is a static structure that contains an identifier, a title, metadata and item elements that reference resources. In the ALOCOM model, a content aggregation combines activities, and an activity combines two types of learning resources, SCOs and assets. Activities, SCOs and assets are content model components and are not represented in RAMLET.

\section{Usage scenario}

Implementing content model mappings is useful in several ways. First of all, share and reuse of learning object components is enabled across systems. For instance, an LMS using SCORM content can be aligned with a Cisco digital library at the content level (see use case 1 in Fig. 18). Equivalent components can be identified and potentially repurposed within different contexts.

Secondly, the ontology is useful as an underlying component model for a global learning object digital library. A decomposition architecture can deconstruct learning objects from different origins according to the ALOCOM model. The availability of these components enables reuse on a global scale. Authoring systems can connect to the digital library, enabling on-the-fly retrieval of relevant components from within authoring tools.

We developed such architecture that supports the approach for both structured learning objects, such as learning objects available in SCORM, and unstructured or semi-structured learning objects, such as presentations or web pages [43]. The architecture supports decomposition of composite learning objects into ALOCOM components and stores the components individually into the digital library, enriched with metadata. Component types and relationships between components are stored in the metadata instance.

Furthermore, on-the-fly access to these components is provided from within mainstream authoring tools, such as MS PowerPoint, MS Word and the RELOAD editor, a packaging tool that enables composition of SCORM learning objects. Authors can search components, such as images, definitions, examples, text fragments, or tables, from within the applications. Components that are found are shown in an integrated window and the author can incorporate them directly into the learning object that is being edited. The ALOCOM plug-in for MS PowerPoint is shown in Fig. 19.

A typical usage scenario goes as follows: Suppose that an author is creating a learning object on differential equations. He/she wants to start with a definition, followed by three examples. The author enters "differential equations" as keywords and selects "definition" and "example" as component types. The system then searches the digital library and retrieves all components of the selected types dealing, with the selected topic. The author then chooses the most relevant components and includes them into the learning object.

RAMLET comes into the scenario when the author wants to export the learning object to a digital library specific format. Using RAMLET, the author is free to choose the publishing format of the generated content assembly among IMS CP, METS, MPEG-21 DIDL and Atom.

\section{Related work}

Some researchers have adopted our initial content model comparison approach presented in [42]. In [35], the Me-thodenlehre-Baukasten model [36] is added to the comparison. Furthermore, the comparison is used as the basis for the development of a new content model, dLCMS. Similar to our work, it is argued that at least three aggregation layers 
Fig. 18 Use cases

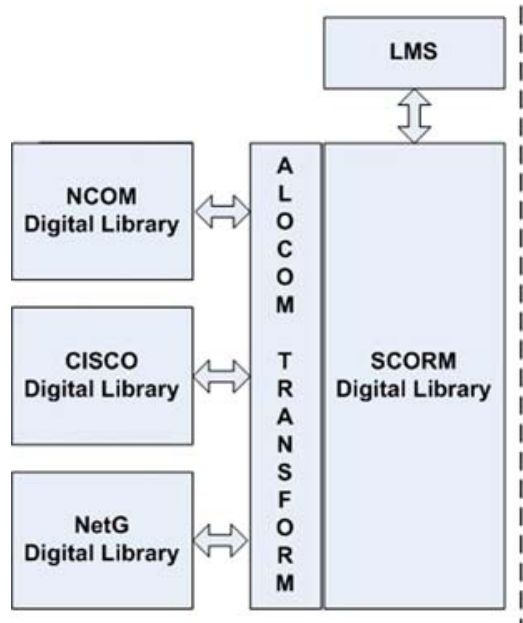

Use Case 1

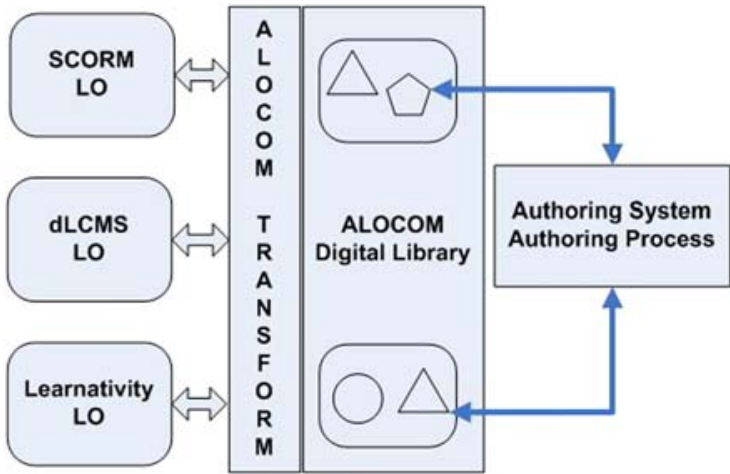

Use Case 2

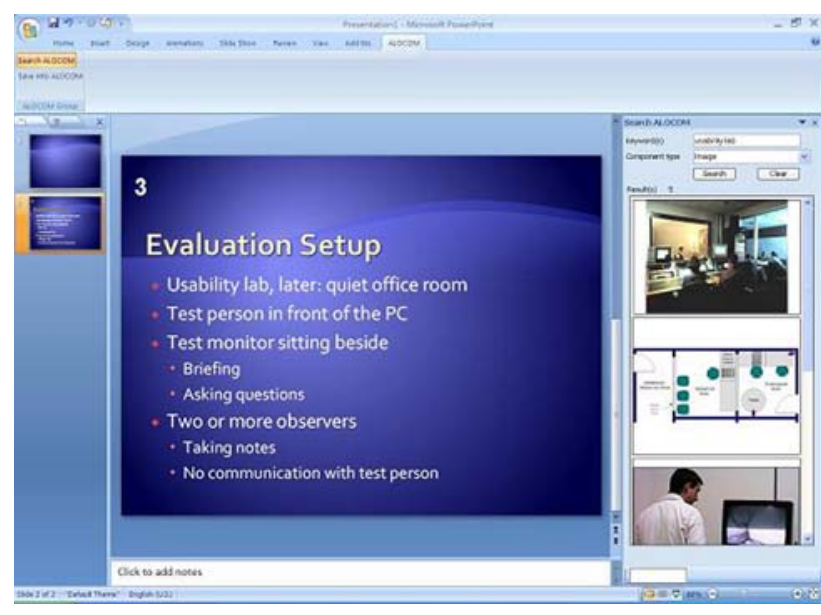

Fig. 19 The ALOCOM plug-in for MS PowerPoint

are required for enabling successful aggregations of learning object components.

In [15], IMS/LD [20] is added to the content model comparison. The authors of the SLM model used the comparison table to compare and contrast their model to existing content models. No changes to the comparison are proposed. Hence, the researchers seem to agree that the alignment of content models included in the first investigation (SCORM, Cisco, NETg and Learnativity) is valid.

Besides content model investigations, ontologies have been built that try to classify learning object components. Overlaps exist between the ontology on instructional items [41] and the ALOCOM model. This ontology defines component types that are situated at the content object and singleobjective LO level. Another example of such ontology is used in the TRIAL-SOLU-TIONS project [23]. This ontology defines component types for mathematical learning objects, including definition, lemma, theorem, proof, corollary, scholium, comment, theory, axiom, postulate, thesis, method, rule, criterion, open question, paradox, example, and solution. The ontology would be a meaningful extension of the ALOCOM model when dealing with mathematical content.

\section{Conclusion}

The ALOCOM model and ontology mappings presented in this paper are an attempt to align existing learning object content models and are aimed at enabling their interoperability. The ontology connects content model specifications that are currently available. Such an ontology is never completely stable and should evolve over time. Furthermore, as it is an attempt to integrate different viewpoints, the mappings are subject to discussion. It is the hope of the authors that interested parties help to improve this work, so as to bring it to its full potential.

Acknowledgments We gratefully acknowledge the financial support of the K.U. Leuven Research Council through the BALO project, the Interdisciplinary Institute for Broadband Technology (IBBT) through the Acknowledge project, and the European Commission through the ProLearn Network of Excellence on Professional Learning [30].

\section{References}

1. Advanced Distributed Learning (ADL). http://www.adlnet.org (2007). Accessed 30 September 2007

2. Ballstaedt, S.-P.: Wissensvermittlung die Gestaltung von Lernmaterial. Weinheim, Beltz PsychologieVerslagsUnion (1997)

3. Barrit, C., Lewis, D., Wieseler, W.: CISCO Systems Reusable Information Object Strategy Version 3.0. Cisco Whitepaper. http://www.cisco.com/warp/public/779/ibs/solutions/learning/ whitepapers/el_cisco_rio.pdf (1999). Accessed 30 September 2007

4. Bechhofer, S., van Harmelen, F., Hendler, J.A., Horrocks, I., McGuinness, D.L., Patel-Schneider, P.F., Stein, L.A., Dean, M., Schreiber, G. (eds.): OWL Web Ontology Language Reference, 
World Wide Web Consortium, Recommendation REC-owl-ref20040210, February 2004

5. Brooks, J., Jesukiewicz, P.: SCORM reuse: current reality, challenges, and best practices. In: Proceedings of the Interservice/Industry Training, Simulation, and Education Conference (I/ITSEC), Florida, 4-7 December 2006

6. Buccella, A., Cechic, A., Brisaboa, N.R.: An ontology approach to data integration. J. Comput. Sci. Technol. 3(2), 62-68 (2003)

7. Cardinaels, K.: A dynamic learning object life and its implications for automatic metadata generation, xvi +163 pp. Ph.D. Thesis, Department of Computer Science, K.U.Leuven, Leuven, Belgium, June 2007

8. Ceusters, W., Bouquet, L.: Language engineering and information mapping in pharmaceutical medicine. J. Belg. Med. Inform. Assoc. 7(1), 26-34 (2000)

9. Clark, R.: Developing technical training: a structured approach for the development of classroom and computer-based instructional materials. Performance Technology Press, New York (1989)

10. Dick, W., Cary, L.: The systematic design of instruction, 3rd edn. Harper Collins, New York (1990)

11. Downes, S.: Learning objects: resources for distance education worldwide. Int. Rev. Res. Open Distance Learn. 2(1) (2001)

12. 1484.12.1 IEEE LTSC Draft Standard for Learning Object Metadata http://ltsc.ieee.org/wg12/files/LOM_1484_12_1_v1_Final_ Draft.pdf (2002)

13. Duval, E., Hodgins, W.: A LOM research agenda. In: Hencsey, G., White, B., Chen, Y., Kovacs, L., Lawrence, S. (eds.) Proceedings of the 12th international conference on World Wide Web, Budapest, Hungary, pp. 659-667 (2003)

14. ELI. EDUCAUSE Learning Initiative. http://www.educause.edu/ eli (2007). Accessed 30 September 2007

15. Fernandes, E., Madhour, H., Miniaoui, S., Forte, M.W.: Phoenix Tool: A Support to Semantic Learning Model. Workshop on Applications of Semantic Web Technologies for e-Learning (SWEL@ICALT'05), Kaohsiung, Taiwan, 5-8 July 2005

16. Gagne, R.: The conditions of learning and theory of instruction. CBS College, New York (1985)

17. Horn, R.: Structured writing at Twenty-five. Perform. Instr. 32, 11-17 (1993)

18. Horn, R.E.: Structured writing as a paradigm. In: Romiszowski, A., Dills, C. (eds.) Instructional development: state of the art. Educational Technology Publications, Englewood Cliffs (1998)

19. IMS-CP. IMS Content Packaging. Information Model, Best Practice and Implementation Guide, XML Binding Schemas, Version 1.1.4 Final Specification, IMS Global Consortium Inc. http:// www.imsglobal.org/content/packaging (2007). Accessed 30 September 2007

20. IMS Learning Design (IMS LD) Specification. http://www. imsglobal.org/learningdesign/ (2003)

21. ISO/IEC 21000-2:2005. Information technology: multimedia framework (MPEG-21) Part 2: Digital Item Declaration. http://standards.iso.org/ittf/PubliclyAvailableStandards/ c041112_ISO_IEC_21000-2_2005(E).zip (2007). Accessed 30 September 2007

22. L'Allier, J.J.: Frame of reference: NETg's map to the products, their structure and core beliefs. NetG whitepaper. Cited in Polsani, Pithamber R. (2003) The Use and Abuse of Reusable Learning Objects. J. Digit. Inf. 3(4)

23. Lenski, W., Wette-Roch, E.: The TRIAL-SOLUTION approach to document re-use principles and realization. In: Proceedings of Electronic Media in Mathematics, Coimbra, 13-15 September 2001

24. Löser, A., Grune, C., Hoffmann, M.: A didactic model, definition of learning objects and selection of metadata for an online curriculum. In: Proceedings of the International Workshop of Interactive Computer Aided Learning (ICL), Villach, Austria 2002
25. Mager, R.F.: Preparing instructional objectives, 2nd edn. David S. Lake, Belmont (1984)

26. Merrill, M.D.: Component display theory. In: Reigeluth, C.M. (eds.) Instructional design theories and models. Erlbaum Associates, Hillsdale, NJ (1983)

27. Metadata Encoding and Transmission Standard (METS). http:// www.loc.gov/standards/mets/mets-home.html (2007). Accessed 30 September 2007

28. Navy Integrated Learning Environment (Navy ILE) Introduction. https://ile-help.nko.navy.mil/ile/ (2007). Accessed 30 September 2007

29. Pazandak, P., Srivastava, J.: Evaluating object DBMSs for multimedia. IEEE Multimed. 4(3), 34-49 (1997)

30. ProLearn: Prolearn Network of Excellence on professional learning. http://www.prolearn-project.org/ (2007). Accessed 30 September 2007

31. Resource Aggregation Model for Learning, Education and Training (RAMLET). http://www.ieeeltsc.org/wg11CMI/ramlet/Pub/. Accessed 30 September 2007

32. Reusable Learning. http://www.reusablelearning.org (2007). Accessed 30 September 2007

33. Rey-López, M., Fernández-Vilas, A., Díaz-Redondo, R., PazosArias, J.: Providing SCORM with adaptivity. In: Carr L, De Roure D, Arun Iyengar, Goble CA, Dahlin M (eds.) Proceedings of the 15th International Conference on World Wide Web, pp. 981-982. ACM Press, New York (2006)

34. Robson, R.: Context and the role of standards in increasing the value of learning objects. In: McGreal R. (eds.) Online Education Using Learning Objects edited. University of Athabasca, Canada

35. Schluep, S.: Modularization and Structured Markup for Webbased Learning Content in an Academic Environment. Shaker, Aachen (2005)

36. Schulmeister, R.: Lernplattformen für das virtuelle Lernen. Evaluation und Didaktik, München (2003)

37. Sharable Content Object Reference Model (SCORM): 2nd edn. http://www.adlnet.org (2004). Accessed 30 September 2007

38. Su, X., Gulla, J.A.: An information retrieval approach to ontology mapping. Data Knowl. Eng. 58(1), 47-69 (2006)

39. Sü $\beta$, C., Kammerl, R., Freitag, B.: A teachware management framework for multiple teaching strategies. In: Bourdeau, J., Heller, R. (eds.) Proceedings of the 12th ED-MEDIA 2000 World Conference on Educational Multimedia, Hypermedia and Telecommunications, Montreal, QC, Canada, pp. 1101-1106, 26 June-1 July 2000

40. Tan, G.H.: Getting Started with Learning Objects. Publication incorporated into SeLF (Singapore e-Learning Framework). http://ole.tp.edu.sg/courseware/teaching_guide/resources/ article/gekhua/Getting\%20Started\%20with\%20LO.pdf (2002). Accessed 30 September 2007

41. Ullrich, C.: The learning-resource-type is dead, long live the learning-resource-type!. Learn. Objects Learn. Des. 1(1), 7-15 (2005)

42. Verbert, K., Duval, E.: Towards a global architecture for learning objects: a comparative analysis of learning object content models. In: Cantoni, L., McLoughlin, C. (eds.) Proceedings of the 16th ED-MEDIA 2004 World Conference on Educational Multimedia, Hypermedia and Telecommunications, Lugano, Switzerland, pp. 202-209 (2004)

43. Verbert, K., Jovanovic, J., Gasevic, D., Duval, E.: Repurposing Learning object Components. In: Spyns, P., Duval, E., de Moor, A., Aroyo, L. (eds.) Proceedings of WOSE05: OTM 2005 Workshop on Ontologies, Semantics and E-Learning, Agia Napa, Cyprus, November 3 2005, pp. 1169-1178. Springer, Berlin (2005)

44. Wagner, E.D.: Steps to creating a content strategy for your organization. e-Learn. Dev. J. (2002) 
45. Wiley, D.A.: Connecting learning objects to instructional design theory: a definition, a metaphor, and a taxonomy. The instructional use of learning objects, Bloomington (2002)
46. Wiley, D.A.: The learning objects literature. http://opencontent. org/blog/wp-content/uploads/2007/07/wiley-lo-review-final. pdf. Accessed 10 September 2007 